\title{
Художественный текст
}

\section{ВНУТРЕННИЙ И ВНЕШНИЙ МИР ПОЭТА БОРИСА РЫЖЕГО}

\author{
Ю.В. Казарин, И.К. Мухина \\ Уральский федеральный университет им. первого Президента России Б.Н. Ельцина, \\ г. Екатеринбург
}

\begin{abstract}
Выявлено, что поэтическое познание обусловлено рядом факторов антропологического, художественного, культурологического, социального, лингвотекстового и онтологического характера. Объектом поэтического познания является триединство Жизнь-Смерть-Любовь, которое в свою очередь порождает бесконечный ряд предметов поэтического познания. Доказано, что внутренний мир и поэтический мир являются системами диффузными, пересекающимися.

Ключевые слова: поэтическое познание, внутренний мир, поэтический мир, денотативнофункииональный комплекс, пересекаемость внутреннего и поэтического миров, параметры поэтического мира, предмет поэтического познания, интертекстуальность, архетекстуальность.
\end{abstract}

Поэтическое творчество основывается на процессах особого вида познания. Художественное познание [1] - это поливалентное состояние гносеологической интенции художника, которое включает в себя результаты других видов познания: научного, социального, бытового, онтологического, этико-эстетического, нравственного, религиозного и многих иных.

Поэтическое познание - это оптимальный, наболее мощный тип художественного познания. В процессе поэтического познания объект и предметы поэтического познания укрупняются в сознании поэта за счет их основных качеств: непознаваемости, невыразимости, неизъяснимости. Главным объектом такого вида познания является триединство Жизнь-Смерть-Любовь, которое в свою очередь порождает бесконечный ряд предметов поэтического познания, таких как человек, природа, четыре стихии (вода, земля, огонь, воздух), душа, дух, Бог, время / пространство, бесконечность, вечность и многие другие.

Каждый поэт в своем творчестве исследует (поэтически, словесно, музыкально, концептуально и т. п.) свой уникальный ряд предметов бытия и познания, который, несомненно, имеет собственные доминанты и константы. При этом поток поэтического познания не всегда равен потоку поэтического сознания, так как и то, и другое детерминировано бесконечным набором факторов - от антропологического до социального и онтологического.

На основе результатов поэтического познания формируется внешний и внутренний мир поэта. Процессуально-логическая модель такого формирования представляется следующим образом: Поэт $\rightarrow$ Поэтическое познание $\rightarrow$ Поэтиче- ский текст $\rightarrow$ Художественная картина мира $\rightarrow$ Поэтическая картина мира $\rightarrow$ Поэтический мир.

Поэтический мир представляет собой единую, общую систему мира и миров поэта как внутренних, внешних, так и промежуточных, имеющих интерфизический характер. Рассмотрим соотношение внутреннего и поэтического миров Бориса Рыжего в качестве пересекающихся систем.

В целом существование, развитие и функционирование внутреннего мира человека и поэта определяются наличием и работой следующих факторов: антропологические (человек мыслящий, человек как таковой); антропосоциальные (человек в социуме); психосоматические (человек и его физиология, психика, психология); нейрофизиологические (человек и его воображение, мышление); нейролингвистические (человек как языковая личность, обладающая способностью номинировать); антрополингвистические (человек как носитель языка, языковой и текстовой способности); антропотекстологические (человек как художник, поэт, текстотворец; человек как текстовая личность), антропокультурологические (человек / поэт как часть и как творец культуры, поскольку текст есть единица культуры [1-3]); этико-эстетические (человек как читатель / поэт как творец, как художник); нравственно-этические (человек / поэт как носитель и охранитель нравственных ценностей) и др. структуры, которые, несомненно, влияют на формирование внутреннего и поэтического миров, в том числе и непосредственная действительность. Несомненно, трудно определить ту или иную группу факторов в качестве доминирующей: каждая деталь, каждый атрибут, каждый факт, всякое событие в жизни поэта (и человека) имеют решающее значение в формировании внутреннего мира поэта. 


\section{Художественный текст}

Внутренний мир и поэтический мир являются системами диффузными, пересекающимися: чем крупнее и совершеннее личность человека, чем богаче и сильнее талант поэта, тем выше степень адекватности мира внутреннего миру поэтическому.

Внутренний мир человека / поэта имеет свои этапы формирования и систематизации (младенческий, детский, подростковый, юношеский, молодежный, зрелый и т. д.). Внутренний мир начинает формироваться с первых дней существования человека / поэта и не останавливается в своем развитии и обогащении. Так, Б. Рыжий умер, будучи молодым человеком, но его внутренний мир вполне соответствовал параметрам внутреннего мира зрелого человека / поэта.

Поэтический мир в свою очередь представляет собой целый или фрагментарный внутренний мир человека / поэта, вербализованный в процессе поэтического текстотворчества. Процесс такой вербализации также имеет свои этапы, стадии и периоды: ювенильное стихотворчество (у Б. Рыжего вполне оригинальное и независимое), подражательное стихотворчество (у Б. Рыжего это тексты, или текстоиды, созданные по устойчивым стихотворным (и тематическим, и содержательным) моделям (форматам) таких поэтов, как В. Брюсов, А. Блок, С. Есенин, В. Маяковский и др.). Следует отметить, что подражательное стихотворчество сознательного характера и типа (например, стилизации) продолжалось в течение всей жизни поэта. При этом образцами, исходными моделями данного вида стихотворчества оказывались тексты таких поэтов, как Д. Давыдов, А. Полежаев, М. Лермонтов, А. Пушкин, Я. Полонский, Ап. Григорьев, Б. Пастернак, О. Мандельштама, Б. Слуцкого, Е. Рейна, А. Кушнера, было также влияние В. Луговского, и Э. Багрицкого, сильнейшее влияние С. Гандлевского и Дениса Новикова, а главное И. Бродского.

Представляется, что эмоциональные, социальные, ценностные, этические, нравственные, эстетические, философские, художественные, эсхатологические, культурологические, лингвистические (когда социальная игра человека в процессе поэтической вербализации преобразовывалась в языковую, литературную и культурологическую игру поэта в тексте и в текстоиде [игровом тексте]), антрополингвистические, творческие и антропотекстологические параметры внутреннего мира Б. Рыжего были вполне адекватны данным параметрам его поэтического мира. Однако высокая степень адекватности внутреннего и поэтического миров Б. Рыжего, тем не менее, не делает их тождественными друг другу.

Базовые точки пересечения внутреннего мира и поэтического мира Б. Рыжего присутствуют в следующих сферах:

1) сочиальной (тяжелая жизнь людей, проживающих в промышленных зонах и на окраинах мегаполиса, в небольших городах и «рабочего типа» поселках Урала);

2) эмоцииональной (дружба, любовь к родным и близким; любовь к жене, к женщине вообще; иррациональная (воображаемая) любовь к Эле; любовь к людям; любовь к родной земле и т. д.);

3) художественной: поэзия, литература (послание поэтам, прямое обращение к поэтам XIX, $\mathrm{XX}$ вв.; диалоги с современными поэтами [О. Дозморовым, А. Леонтьевым, Е. Извариной, А. Кузиным, Е. Тиновской и др.]);

4) эсхатологической (сверхпристальное внимание Б. Рыжего к смерти и всему, что с ней связано - похороны, траурная музыка, траурные цветы и т. п.; предчувствие своей смерти, пророческое согласие и единение с наступающей смертью);

5) в сфере музыки (во всех ее проявлениях: песни, классическая музыка, музыкальные инструменты, а также музыка города, природы; музыка иррационального характера: воображаемая, связанная с колористкой («голубое, белое, синее»), со светом, с тьмой и т. д.);

6) в сфере музы́ ки (сверхмузыки, метамузыки того, что объединяет в одно целое горе, счастье, любовь, поэзию, красоту, людей, мир).

Ядерной сферой пересечения миров внутреннего и поэтического Б. Рыжего является денотативно-функциональный комплекс «музыка - музы́ ка,, представляющий собой своеобразную концептуальную парадигму, поскольку данные поэтические смыслы выступают идентификаторами всех указанных выше ведущих смысловых блоков - эмотивных, социальных, эсхатологичсеких и этико-эстетических.

Вербализация внутреннего мира человека / поэта в поэтическом текстотворчестве - это процесс, детерминирующий не только денотативносигнификтивную стадию номинации [5, с. 398 402], но и собственно номинацию как именование. Силой и энергией особого, художественного и поэтического состояния языка и языковой (или текстовой, поэтической, культурной) личности поэтическая номинация и вербализация не искажает денотативную составляющую мира, а укрупняет ее за счет повышенной эмотивности, образности, экспрессивности, модальности и концептуальности процессов поэтического познания и поэтической номинации, что и происходит при создании поэтического текста, имеющего уникальные признаки [4] экспериментальности, эвристичности, энигматичности, комплетивности, цельнооформленности, идиоматичности, герметичности, репродуктивности, графичности.

При высокой степени пересекаемости, а также соответствия, совпадения внутреннего и поэтического миров Б. Рыжего точками их пересечения являются следующие лингвистические доминанты и константы: музыкка, музыі ка, поэзия, любовь и смерть.

Что касается внутреннего мира поэта - вербализованного или поэтизированного ядра его 
поэтического мира - он может быть познан в процессе исследования составляющих его биографических, поэтологических и текстовых фактов. Основой поэтического мира Б. Рыжего (фактологической, денотативной, концептуальной, идеологической, творческой, эмоциональной, образной и текстообразующей) выступает его внутренний мир. Сопоставление поэтического и внутреннего мира поэта позволяет выявить, как точки их пересечения, так и фрагменты дифференцирующего характера. Следует отметить, что пересечений оказывается больше: в целом внутренний мир Б. Рыжего на 90 \% количественно и качественно включен в его поэтический мир. Как видно, десятипроцентный «дифференциал» остается невербализованным, представляя собой такие факты и события жизни поэта, которые имеют крайне интимный, «тайный», энигматический характер.

С точки зрения поэтической вербализации внутренний мир поэта вступает с поэтическим миром в родо-видовые отношения. В сфере познания предметы мира, бытия и невыразимого как основного объекта художественного познания постигаются одновременно и человеком, и поэтом в рамках одной языковой и текстовой личности. В процессе поэтического познания мир внутренний и мир поэтический вступают в более сложные родородовые отношения с элементами эквиполентности (пересечения).

Следует подчеркнуть, что поэтическое (художественное) познание как своеобразный процессуальный «движитель» и ядро любой гносеологической деятельности в целом и текстотворчества в частности принципиально невыразимого. Именно категория невыразимого формирует общую основу жизни, деятельности и творчества поэта.

Выявляя основные параметры поэтического мира, необходимо отметить, что сложнейшая природа поэтического мира обусловлена наличием трех групп факторов: внутренних (антропологических, поэтологических), внешних (языковая картина мира, поэтическая картина мира) и промежуточных (лингвотекстовые системы и структуры; просодические особенности; собственно поэтический текст как система поликодового характера).

Как целостное явление поэтический мир формируется на основе системной парадигмы мира языка; мира поэта / человека; мира поэта; мира времени / пространства; мира природы; мира города; мира музыки; мира просодии; мира образов (денотативно-функционального мира); мира концептов; мира смыслов; мира гармонии; духовного мира; мира эмоций; мира религии; мира этики и эстетики; мира онтологии; реального мира; ирреального мира; мира поэзии; воображаемого мира; мира памяти; мира искусства; мира общества; мира семьи; мира государства; мира культуры и мн. др. Параметры поэтического мира, таким образом, имеют множественный, системный характер.
Если поэтический мир - это синтез, совокупность трех разновидностей мира - реального, лингвотекстового (промежуточного) и содержательного (контента и его интерпретации), то в укрупненном (то есть категориальном) виде параметры мира и миров поэта представляются следующим образом: группа поэтологических параметров (жизнь и судьба поэта, события и факты биографического характера); группа лингвотворческих параметров (этапы или периоды творчества; этико-эстетический сценарий стихотворения, цикла стихотворений, всего творчества поэта) и групnа художественных параметров (хронотопичность; эмотивность, концептуальность, образность, тематичность и др.).

Комплексный характер поэтического мира определяется прежде всего полисубъектной природой [7, с. 444-447] поэтического познания и поэтического текстотворчества; это обусловлено тем, что языковая личность поэта включает в себя несколько субъективных (ролевых) структур: человек - поэт - редактор - читатель и др. В качестве генеральной выступает противопоставление человек - поэт, а полисубъектность языковой личности поэта основывается на явлении стереоскопичности (объемности, рельефности) текстовой и поэтической личности.

Текст есть единица не только языка и речи, но и культуры, поэтому языковая личность текстотворца приобретает статус текстовой личности, следовательно, текстовая личность, создающая художественно и исторически значимые тексты, является личностью культуры. Личность культу$p b l$, поэтическая личность формирует в своем творчестве - совокупности поэтических текстов особую языковую картину мира - картину мира культуры, или поэтическую, языковую картину культуры.

Познание мира языковой личностью, в отличие от личности текстовой и поэтической, обладающих большей свободой, осуществляется с учетом прагматических факторов. В гносеологическом и когнитивном отношении языковая личность поливалентна, тогда как текстовая личность и поэтическая личность моновалентны. Познавательная энергия поэтической личности интенционально направлена прежде всего на вербально-просодическое освоение основных предметов бытия.

Именно бытие, а не социум или социальные отношения, является объектом поэтического познания, который включает в себя следующие предметы: природные стихии (земля, вода, огонь, воздух); стихии тех или иных ментальных состояний (сон как видение, предчувствие, восприятие предзнаменований, тайна, всеведение, озарение, прозрение, вдохновение, судьба, рок, творчество как творческая страсть, творческие процессы психологического и креативного характера и многие другие); генеральные предметы - а) жизнь (тайна 


\section{Художественный текст}

жизни, сроки жизни, существование, наличие, живая материя, сознание, память и т. д.), б) смерть (в физическом и онтологическом отношении), в) любовь (в физическом, психологическом, эмотивном, социальном, метафизическом и онтологическом отношении); время во всех своих формах и функциях; пространство во всех функциях и проявлениях; вечность (бессмертие, бездна и т. д.); бесконечность (бездна); детство (как особое состояние времени, жизни и любви); небесные светила, объекты и явления (так, облака у Б. Рыжего - одно из наиболее частотных проявлений образности, концептуальности); осадки (например, снег, дождь у Б. Рыжего как постоянный «второй субъект» в лирической фабуле стихотворения); красота во всех своих функциях и проявлениях; ужас (страх, безобразное, отвратительное, ужасное и т. п.); душа; дух; Бог; Судьба. Фатум. Рок; музыка во всех ее функциях и проявлениях; нежность как метаэмоция через глобальное ощущение и представление данной эмоции; женщина (мать, жена; у Б. Рыжего Ирина, Нина, Эля и др.); ребенок (сын - у Б. Рыжего); дружба (друг, друзья: для Б. Рыжего О. Дозморов, А. Леонтьев, Р. Тягунов и др.); игра (литературная, денотативная, языковая, просодическая); городской пейзаж (улица; у Б. Рыжего с точным адресом, названием; город, например, Уфалей, Свердловск и т. д.); сквер, двор, скамейки, деревья, кусты, цветы и т. п.; поэты (у Б. Рыжего Б. Слуцкий, И. Бродский, Е. Рейн, А. Кушнер и др.); поэзия как онтологическое явление; литература как явление социальное; похороны (у Б. Рыжего - как образ смерти, конца; как праздник скорбный и неизбежный; как символ конца света; как ритуальный процесс, неизбежный и притягивающий внимание); социальная роль поэта (хулигана, пьяницы, почти бунтаря; как существа уникального, тонкого, хрупкого, ангельски чистого и т. п.); человек и поэт в рамках одной и единой языковой личности и мн. др.

Следует подчеркнуть, что все указанные объекты поэтического познания стремятся одновременно и к синтезу, и к распаду; интегративная природа данных предметов очевидна: их видовая и партитивная сущность в процессе функционирования проявляется и в партитивности, и в аспектуальности предмета по отношению к объекту (жизнь - смерть - любовь).

Борис Рыжий постигает указанные предметы познания и в онтологическом, и в антропологическом, и в психологическом, и в социальном, и в этико-эстетическом, и в собственно поэтическом (гносеологическом и когнитивном) отношении.

Моновалентность поэтического познания поэта обусловлена полисубъектной природой поэтического творчества (текстотворчества) в целом. Наличие в языке, в языковой деятельности человека креативной (творческой) функции (Ю.М. Лотман [6]), функции эстетической (Р. Якобсон [8]) и функции этической (Ю.В. Казарин [4]) указывает и на универсальность языковой личности, и на ее комплексный характер и природу.

Человек и язык существуют и функционируют в единстве, так как человек есть одновременно родитель, носитель и пользователь языка. Такая тройственность языковой личности не противоречива, а, напротив, каузативно обусловлена: родитель $\rightarrow$ носитель $\rightarrow$ пользователь (или: мыслитель $\rightarrow$ номинатор $\rightarrow$ коммуникатор). Языковая деятельность, преобразующаяся в деятельность текстовую, изменяет лингвокультурный статус языковой личности, которая теперь, в отличие от личности речевой, функционирует как текстовая личность. Сфера языковой деятельности, включая всевозможные коннотации, определяет статус языковой личности, которая, выходя за пределы онтологической сферы, начинает работать в сфере культуры (как текстовая личность) и / или в сфере социальных коммуникаций (как речевая личность). В этом процессе сфера бытия или сужается до социальной сферы или преобразуется в сферу культуры: бытие определяет природу языковой личности, социум - природу речевой личности, культура - природу текстовой личности, которая всегда и постоянно стремится к состоянию и статусу личности культуры.

Человек и поэт - это два взаимообусловленных, единосистемных и конститутивных состояния языковой личности, речевой личности, текстовой личности и личности культуры. Реально осуществляемые в течение многих лет наблюдения за поэтической личностью в антрополингвистическом, антропоцентрическом, психологическом, социологическом и поэтологическом плане показали, что человек и поэт как два структурноличностных образования в системе поэтической личности постоянно находятся в функциональном, противоречивом, но взаимнодеятельностном состоянии. Естественно, при этом нельзя отделять личность человека от личности поэта - представляя собой одно целое, в сущностно-природном отношении наличествующие в рамках одной системы «человек - поэт» данные «субъекты» дифференцируются:

- человек - существо физическое, поэт - метафизическое;

- человек - существо интеллектуальное, психологическое, эмоциональное, социальное, креативное, деятельностное и т. д., тогда как поэт существо метаинтеллектуальное, метапсихологическое, метаэмоциональное, метасоциальное, метакреативное / творческое, метадеятельностное и т. п.;

- человек функционально универсален: может существовать одновременно в разных сферах бытия - онтологической, социальной и в культурной, тогда как поэт - моновалентен в функциональном отношении и существует только в сфере словесности и культуры.

Важно подчеркнуть, что в культуре различаются несколько видов стихотворной деятельности, 
которые по степени своей подлинности, естественности, а главное - по характеру объекта и предмета художественного познания, - противопоставляются деятельности поэтической. Литература - это художественная словесность, существующая в социальной сфере эстетики, этики, экономики, моды и т. П. Поэзия - это художественное познание невыразимых предметов бытия; поэзия вне рыночных отношений, она равнодушна к моде и бесценна; поэзия существует в сфере бытия и культуры, минуя экономически обусловленные парадигмы литературы, беллетристики, сетературы и иных видов аттрактивной словесности. Поэзия реализуется в тексте (поэтическом, прозаическом, драматургическом); литература реализуется в текстоидах, совокупность которых создают особые социально детерминированные сферы культуроидов (см. культуроиды хипстеров, постмодернистов, фестов, литературных баттлов, квестов, перформеров и т. д.). Поэт, тем не менее, способен создавать и поэтические тексты, и тексты литературные (в процссе стихотворчества, стихописательства), и текстоиды. Например, Борис Рыжий является как раз образцом того поэта, который оставил и стихотворения литературного характера, и стихотворения-текстоиды, и собственно поэтические тексты.

Человек и поэт в общей системе и различных структурах языковой личности находятся в состоянии оппозиции, в которой в разных условиях реализуются различные отношения, среди которых выделяются следующие.

1. Отношения тождества, подразумевающие творческую адекватность одного статуса языковой личности другому; этико-эстетическую гармонию человека и поэта в системе одной языковой и текстовой личности, личности культуры; «взаимную поддержку» в процессе жизни, социальной деятельности и поэтического текстотворчества.

2. Отношения гиперо-гипонимии, когда один из статусов языковой, текстовой личности, личности культуры включается в качестве родового в другой, видовой, нанося несомненный ущерб или жизни (человека), или судьбе (поэта). В таком случае счастливое равновесие нарушается: доминирует или человек (поэту «плохо»), или поэт (человеку «плохо»). Это наиболее распространенный тип отношений в данной оппозиции, чреватый возникновением конформизма социального (человек $\geq$ поэта) или появлением феномена эскапизма, замкнутости, затворничества поэта (поэт $\geq$ человека). Так, Борис Рыжий чаще находился именно в таком виде отношений человека и поэта в своей языковой, текстовой личности, личности культуры.

3. Отношения эквиполентности, проявляющиеся в том, что человек и поэт в одной языковой, текстовой личности, личности культуры находятся в состоянии партитивного тождества, различаясь незначительными компонентами (ср. в этой связи отношения паронимии в лексике). Такие отноше- ния чреваты неожиданными катастрофами житейского и творческого характера. Вместо амортизации (как это наблюдается в двух первых видах отношений) в этом случае возникает накопление негативной энергии нежизненного и нетворческого характера.

4. Отношения дизъюнктивности, при которых человек и поэт в одной языковой личности, текстовой личности, личности культуры абсолютно автономны: человек крайне отрицательно относится к текстотворчеству и отрицает в себе поэта, тогда как поэт крайне негативно относится к себе как к человеку. Такое трагическое несовпадение двух личностных структур - антропологической и поэтологической - приводит, как правило, к забвению поэтического таланта, к его гибели. Иногда в таких случаях гибнет сам человек.

Стереоскопичность, комплексность, неоднородность, оппозитивность - вот характеристики функционально-денотативной природы субъекта текстотворчества в целом и поэтического творчества в частности, которые находят проявление и в речевой деятельности. Так, в речи существуют устойчивые фраземы, которые характеризируют двойственную, иногда и множественную, природу творчества: загубить талант, пропить талант, убить в себе поэта / художника, зарыть талант в землю, растратить талант и др. Но есть и другие выражения: талант не пропьешь (и др. более грубые формы), которые, как правило, называют талант, погубленный самим человеком, но погубленный не до конца, до некоего мизерного остатка.

Борис Рыжий как поэт, как языковая личности, текстовая личность выступает как творческая натура весьма противоречивого характера, в связи с чем в его творчестве проявляется полисубъектная природа текстотворца, когда человек и поэт в системе языковой, текстовой, поэтической личности или личности культуры вступают во все виды отношений, характерные для оппозиции человек поэт. Возможно, высокая степень трагичности восприятия и создания собственного мира и своих поэтических миров, а также самоубийство в возрасте 26 лет могут быть объяснены в том числе и таким образом.

Выделим функционально-денотативные роли Б. Рыжего как субъекта поэтического творчества (см. таблицу).

Если О.Э. Мандельштам вступает в дуэльные отношения с государством (как А.С. Пушкин - с Геккеренами) для того, чтобы, убивая свою плоть, спасти свою поэзию, время своей поэзии и свою поэтосферу, - то Б. Рыжий вступает в дуэльные отношения прежде всего с собой, а также с миром пошлости и подлости. Б. Рыжий кончает свою жизнь самоубийством в 2001 г. (7 мая). Человек убил поэта или поэт убил человека, вот главная загадка этой трагической жизни, любви и смерти.

Поэтологическая картина жизни и судьбы Б. Рыжего, сформированная на основе личных на- 


\section{Художественный текст}

Функционально-денотативные роли Б. Рыжего

\begin{tabular}{|l|l|}
\hline \multicolumn{1}{|c|}{ Человек } & \multicolumn{1}{|c|}{ Поэт } \\
\hline Гражданин СССР, позднее РФ & Читатель, поэт \\
\hline Сын профессора и врача & Читатель, стихотворец (просодическая игра) \\
\hline Учащийся средней общеобразовательной школы & Стихотворец-подражатель (просодическая игра) \\
\hline Член дворовой компании & Стихотворец (языковая игра) \\
\hline Студент вуза & Стихотворец (литературная игра), поэт \\
\hline Муж, глава семьи (жена Ирина, сын Артем) & Стихотворец, поэт \\
\hline Отец (сын Артем) & Поэт \\
\hline Аспирант & Стихотворец (литературная игра), поэт \\
\hline Литератор (сотрудник газеты, журнала «Урал») & Поэт (языковая, литературная игра) \\
\hline Известный литератор, стихотворец & Стихотворец, поэт \\
\hline $\begin{array}{l}\text { Известный поэт, автор книги, лауреат литератур- } \\
\text { ной премии }\end{array}$ & Поэт, стихотворец \\
\hline Поэт (после гибели) & Поэт, стихотворец, писатель \\
\hline и др. & \\
\hline
\end{tabular}

блюдений, на основе рассказов ближайшего друга Б. Рыжего - Олега Дозморова, известного поэта, проживающего в Лондоне, в ходе бесед с родными поэта: отцом Борисом Петровичем, матерью Маргаритой Михайловной, женой Ириной, сыном Артемом, сестрами Ольгой и Еленой; кроме того, на воспоминаниях друзей и знакомых поэта - Е. Тиновской, Е. Извариной, В. Блинова, Н. Смирновой и многих других, свидетельствует о том, что Б. Рыжий сознательно выстраивал свою жизнь (человека) и поэтическую судьбу (поэта).

Б. Рыжий хотел стать и быть профессиональным литератором (мечта многих молодых поэтов, понимающих, что на гонорары от стихотворных публикаций не проживешь). Профессиональный литератор, по Б. Рыжему, это он, поэт, работающий в редакции газеты, журнала или издательства, активно и много пишущий (рецензии, статьи, эссе, прозу) и публикующий свои литературные опусы. Однако в Екатеринбурге такой жизненный сценарий был невозможен: единственный журнал «Урал» и ряд самодельных издательств (все это малобюджетные организации) не могли быть сферой, в которой бы мог существовать «чистый» литератор. Б. Рыжий хотел (мечтал? планировал?) переехать в Санкт-Петербург, в Москву, где литературно-социальные сферы развиты более широко и глубоко, - но не мог этого сделать: держали две семьи - своя и родительская (отец перенес ряд инфарктов). Борис был накрепко привязан к столице Среднего Урала и жил, постоянно ощущая помощь отца, Бориса Петровича, - помощь разнообразную и серьезную. Вещество жизни поэта (и человека) Б. Рыжего крутилось на месте: казалось, что там, где должна быть жизнь, образовалась, как в артерии, бытовая, обывательская аневризма, наличие которой известно к чему приводит.

Б. Рыжий, поэт, также планировал, вернее, определял четкие параметры своих стихотворений. Стратегически (по совету старших товарищей, например, стихотворца Ю.Л. Лобанцева и др.) поэт был обязан создавать стихотворения, содержащие аттрактивные элементы - для привлечения внимания публики. Стихи должны «нравиться» слушателю и читателю. Тактически Б. Рыжий усилил хронотопическую, денотативную и жанровую сферы стихотворений, обязательно и постоянно употребляя в стихах реальные топонимы; времена года и периоды истории семьи, города, страны; имена собственные - антропонимы, называющие реальные лица и персонажи исторического / литературного характера. Эти опознавательные знаки времени, места, людей и вообще эпохи позволяли поэту создавать тексты с высокой степенью подлинности, достоверности и «жизненности».

Б. Рыжий использовал известную историколитературную формулу поэта Е. Рейна: все забыть и начинать писать с В. Луговского, т. е. с 20-30-х гг. $\mathrm{XX}$ в., продолжая линию сюжетных стихотворений, усиливая этот поток фабульно-лирических текстов за счет старого, забытого - нового для конца XX в. - этико-эстетического сценария, опирающегося на утверждение «Жизнь и поэзия - одно» или «Поэзия - оправдание и оправдыватель жизни».

Стихи Б. Рыжего появились в тот момент, когда «советская» поэзия (идеологизированная, социологизированная) начала заметно отступать под натиском постмодернизма и «поэзии» новой, иной рыночной, ориентированной в большей степени на результат не этико-эстетический, но - экономический. Главное (в конце девяностых годов XX в.) в стихах Б. Рыжего - жизненность, открытость эмоциональная и духовная, прямоговорение и литературная, языковая, культурологическая игра.

Просодическая тактика Б. Рыжего основывается на использовании хорошо забытого старого (т. е. в условиях 90-х гг. ХХ в. - нового): Б. Рыжий синтезировал устойчивые просодические модели XIX (золотого), начала XX (Серебряного), середины XX (Свинцового) и конца XX («постбродского» периода) веков. Б. Рыжий заимствовал метро- 
ритмические, строфические и в целом музыкальные модели поэтов XIX в. (Денис Давыдов, К. Батюшков, А. Полежаев, Я. Полонский, А. Фет и др.); поэтов XX в. (В. Брюсов, Б. Пастернак, Э. Багрицкий, С. Есенин, В. Маяковский, В. Луговской, Н. Заболоцкий, Б. Слуцкий, Е. Рейн, И. Бродский, Денис Новиков и др.); поэтов-современников-ровесников (А. Леонтьев, О. Дозморов, Р. Тягунов и др.).

Поэзии Б. Рыжего свойственна многоуровневая интертекстуальность (Федор Сологуб как-то пошутил: вот придет поэт, который всех обворует, и это будет новый Пушкин).

Поэзия (вербализованная) - занятие почти коллективное: поэт нуждается как в интертекстуальности своего текстотворчества, так и в архетекстуальности (наличие в тексте архетекстуальной, архетипической парадигмы: генетика, генезис, влияние культуры, литературы и ряда метатекстовых образований, без которых акт творчества не состоится, таких как текст-культура, текстзамысел, текст-промысел, текст автора, текст читателя, текст опубликованный (текст-книга), текст оптимальный и архетекст), а также в наличии крепких связей в межтекстовых и в межпоэтологических отношениях. Прямо говоря, поэт есть часть глобальной поэтологической парадигмы (в рамках данной словесной культуры и поэтосферы); творчество поэта есть часть поэтосферы данной словесной культуры («культуры поэзии»); каждая единица творчества есть элемент пересечения, парадигматики, синтагматики и в целом синтактики, которые реализуются между текстами одного / нескольких / всех авторов, работавших и которые будут работать в сфере данного языка, данной речи, данного текстотворчества и данного культуростроения.

Интертекстуальные связи осуществляются человеком, содержащим в себе поэта, а остальные указанные связи глобального характера осуществляются поэтом (поэтическим состоянием человека).
Итак, поэтическое познание обусловлено рядом факторов антропологического, художественного, культурологического, социального, лингвотекстового и онтологического характера, когда факторы, условия и причины такого познания синтезируются в одно целое (в единый цельный процесс) на базе доминирующего фактора онтологической или бытийной природы.

Исследование выполнено за счет гранта Российского научного фонда (проект №16-18-02005).

\section{Литература}

1. Бабенко, Л.Г. Филологический анализ текста. Основы теории, приниипы и аспекты анализа: учеб. для вузов / Л.Г. Бабенко. - М.: Академический Проект; Екатеринбург: Деловая книга, 2004. $464 c$.

2. Болотнова, Н.С. Основы теории текста / Н.С. Болотнова. - Томск: Изд-во Томского гос. пед. ун-та, 1999. - $100 \mathrm{c}$.

3. Гальперин, И.Р. Текст как объект лингвистического исследования / И.Р. Гальперин. - М.: Наука, 1982. - 140 c.

4. Казарин, Ю.В. Основы текстотворчества (мастерская текста) / Ю.В. Казарин. - Екатеринбург: Гуманитар. ун-т, 2008. - 204 c.

5. Казарин, Ю.В. Филологический анализ поэтического текста: учеб. для вузов / Ю.В. Казарин. - М.: Академический Проект; Екатеринбург: Деловая книга, 2004. - 432 с.

6. Лотман, Ю.М. Внутри мыслящих миров. Человек - Текст - Семиосфера - История / Ю.М. Лотман. - М.: Языки русской культуры, 1999. $-448 \mathrm{c}$.

7. Фуко, М. Воля к истине: по ту сторону знания, власти и сексуальности: работы разных лет / М. Фуко; сост. и пер. с франц. С. Табачниковой. - М.: Касталь, 1996. - 448 с.

8. Якобсон, Р. Работы по поэтике / Р. Якобсон. - М.: Прогресс, 1987. - 461 с.

Казарин Юрий Викторович, доктор филологических наук, профессор кафедры фундаментальной и прикладной лингвистики и текстоведения, Уральский федеральный университет им. первого Президента России Б.Н. Ельцина» (Екатеринбург), said55@уа.ru

Мухина Ирина Константиновна, кандидат филологических наук, доцент кафедры фундаментальной и прикладной лингвистики и текстоведения, Уральский федеральный университет им. первого Президента России Б.Н. Ельцина (Екатеринбург), golst@e1.ru

Поступила в редакцию 27 июня 2017 г. 


\title{
INTERNAL AND EXTERNAL WORLDS OF BORIS RYZHY
}

\author{
Yu.V. Kazarin, said55@ya.ru \\ I.K.Mukhina,golst@e1.ru \\ Ural Federal University named after First President of Russia B.N. Yeltsin, \\ Ekaterinburg, Russian Federation
}

The authors argue that poetic knowledge is determined by several factors of anthropological, fictional, cultural, social, linguistic, textual and ontological nature. The object of poetic knowledge is the trinity 'Life-Death-Love' which generates infinite series of poetic knowledge subjects. The authors prove that the internal world and the external world are intersected and diffusive systems.

Keywords: poetic knowledge, internal world, poetical world, denotative and functional complex, intersection of internal and poetic worlds, parameters of poetic world, subject of poetic knowledge, intertextuality, archetextuality.

\section{References}

1. Babenko L.G. Filologicheskiy analiz teksta. Osnovyi teorii, printsipyi $i$ aspektyi analiza: Uchebnik dlya vuzov [Philological Analysis of the Text. Theory Bases, Principles and Aspects of the Analysis: The Textbook for Higher Education Institutions]. Moscow, Academic Project Publ., Ekaterinburg, Business book Publ., 2004.464 p.

2. Bolotnova N.S. Osnovyi teorii teksta [Bases of the Theory of the Text]. Tomsk, the Tomsk State Pedagogical University Publ., 1999. 100 p.

3. Galperin I.R. Tekst kak ob'ekt lingvisticheskogo issledovaniya [Text as Object of a Linguistic Research]. Moscow, Science Publ., 1982. 140 p.

4. Kazarin Yu.V. Osnovyi tekstotvorchestva (masterskaya teksta) [Tekstotvorchestvo Bases (Text Workshop)]. Ekaterinburg, Humanities University Publ., 2008. 204 p.

5. Kazarin Yu.V. Filologicheskiy analiz poeticheskogo teksta: uchebnik dlya vuzov [Philological Analysis of the Poetic Text: The Textbook for Higher Education Institutions]. Moscow, Academic Project Publ., Ekaterinburg, Business Book Publ., 2004. 432 p.

6. Lotman Yu.M. Vnutri myislyaschih mirov. Chelovek - Tekst - Semiosfera - Istoriya [In the Conceiving Worlds. The Person - the Text - Semiosfera - History]. Moscow, Languages of the Russian Culture Publ., 1999. $448 \mathrm{p}$.

7. Fuko M. Volya $k$ istine: po tu storonu znaniya, vlasti $i$ seksualnosti: Rabotyi raznyih let [Volya to the Truth: on that Side of Knowledge, the Power and Sexuality: Works of different years]. Moscow, Kastal Publ., 1996. $448 \mathrm{p}$.

8. Yakobson R. Rabotyi po poetike [Works on poetics]. Moscow, Progress Publ., 1987. 461 p.

Yury V. Kazarin, Doctor of Philology, professor, the chair of Fundamental and Applied Linguistics and Tekstovedeniye, Ural Federal University named after First President of Russia B.N. Yeltsin (Ekaterinburg), said55@ya.ru

Irina K. Mukhina, Candidate of Philology, associate professor, the chair of Fundamental and Applied Linguistics and Tekstovedeniye, Ural Federal University named after First President of Russia B.N. Yeltsin (Ekaterinburg),golst@e1.ru

Received 27 June 2017

\section{ОБРАЗЕЦ ЦИТИРОВАНИЯ}

Казарин, Ю.В. Внутренний и внешний мир поэта Бориса Рыжего / Ю.В. Казарин, И.К. Мухина // Вестник ЮУрГУ. Серия «Лингвистика». - 2017. - Т. 14, № 3. C. 5-12. DOI: $10.14529 /$ ling170301

\section{FOR CITATION}

Kazarin Yu.V., Mukhina I.K. Internal and External Worlds of Boris Ryzhy. Bulletin of the South Ural State University. Ser. Linguistics. 2017, vol. 14, no. 3, pp. 5-12. (in Russ.). DOI: 10.14529/ling170301 